\title{
THE EUDOXOS PROJECT
}

Teaching Science in Secondary Education through a Robotic Telescope
N. Andrikopoulos ${ }^{1}$, M. Apostolakis ${ }^{1}$, S. Savvas ${ }^{1}$, S. Sotiriou ${ }^{1}$
G. Fanourakis ${ }^{2}$, T. Geralis ${ }^{2}$, P. Georgopoulos ${ }^{2}$, P. Kokkinias ${ }^{2}$, A. Markou ${ }^{2}$, M. Pappa ${ }^{2}$, N. Solomos ${ }^{2}$, K. Zaxariadou ${ }^{2}$
G. Kalkanis ${ }^{3}$
E. Garcia Cruz ${ }^{4}$, J. Felix Angulo Rasco ${ }^{4}$, C. Rodriguez Gonzalez ${ }^{4}$

'Ellinogermaniki Agogi, Douk. Plakentias 25, 15234 Chalandri, Greece; ${ }^{2}$ Institute of Nuclear Physics, NRC "Demokritos". Athens 15310, Greece; "University of Athens, Pedagogical Department, 3 a Navarinou St., Athens 40680, Greece; ${ }^{4}$ University of Cadiz, Facultad de CC. de la Education. Departamento de Didactica, Campus Puerto Real. 11519, Puerto RealCadiz, Spain

\begin{abstract}
The Eudoxos project aims at using the possibilities the Internet offers in order to transform the classroom into a research laboratory. The project studies the applicability of the emerging technology in the school sector and provides a platform that allows the students to use the Robotic Telescopes of the Eudoxos National Observatory for Education and Research in the framework of their school curriculum. The robotic telescopes are installed in the Eudoxos National Observatory for Education and Research on the Ainos mountain of Kefallonia Island (Ionian Sea), Greece, performing night sky as well as solar observations.
\end{abstract}

Key words: robotic telescopes, e-learning environment, interdisciplinary learning 


\section{PROJECT'S DESCRIPTION AND OBJECTIVES}

The main aim for the Eudoxos project is to take advantage of the popularity of the subject of Astronomy and the attraction of the idea of using directly a first rate scientific instrument, in particular a high grade telescope, to teach students concepts and ideas of science, of a multidisciplinary nature spanning through the areas of mathematics, statistics, chemistry, physics etc. and of cource astronomy, astrophysics and cosmology.

\section{PROJECT'S PEDAGOGICAL APPROACH}

In new technology application of Eudoxos project supports the pedagogical method of autonomous self-directing learning and allows for a self-directed acquisition of skills to meet users individual communication and learning needs. A learner support is supplied through an on-line manual that acts as an on-line tutor. The on-line tutor serves as the guide to the students' work. Methodologically it is based on the learning scenarios and the lesson plans that have been developed in order to support the project's application.

\section{STUDENTS' ACTIVITIES}

In the framework of the project a user-friendly web based educational environment is being developed in order for the telescopes to be operated via queue based scheduling by high school students and their teachers. The project's implementation includes two cycles of school-centered work in real school environments. For the first cycle an adapted curriculum have been developed around a solid educational framework that captures the main learning objectives of the project (observation of the sun, the moon, planets, galaxies, nebulae, variable stars, eclipsing binaries), while during the second cycle the students and teachers of the participating schools have the chance to design and perform their own projects by using the telescope (as for example the determination of the orbital elements of asteroids and other ambitious projects and experiments) from their own direct astronomical observations.

The pedagogical framework includes the necessary adjustements to the normal school curriculum, teachers training (on-line seminars and workshop) and support, development of lesson plans for the project's implementation in the classroom and development of educational material (conventional and electronic). 